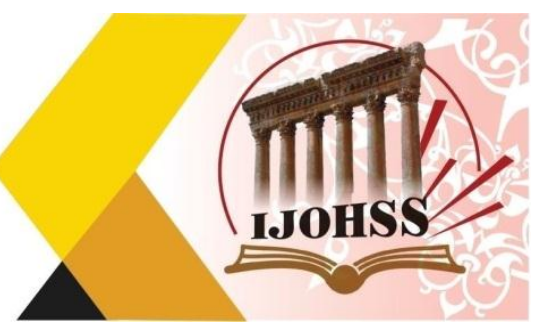

\title{
Post-Traumatic Risk Factors in Heroin Addiction Patients Undergoing Substitution Treatment
}

\author{
Firas Abbas Fadhil \\ University of Technology - Iraq \\ Emil : firasabbas68@yahoo.com
}

\begin{abstract}
Opioid addiction is a real public health problem and studies on its risk factors are needed. Scientific work addressing the links between heroin addiction from the angle of the impact of traumatic events and post-traumatic consequences, risk factors often apparent in the clinic, has focused more on specific populations in the Arab countries, and more rarely in Iraq. This research therefore focused on studying post-traumatic risk factors in heroin-addiction patients undergoing substitution treatment through cross-sectional study. This study concerned a set of 30 heroin-addiction patients on Opioid Substitution Treatment OST during their treatment at Ibn Rushd Psychiatric Hospital Teaching IRPHT in Baghdad. We hypothesized that opioid addiction correlated with traumatic events, psychiatric disorders and socio-demographic determinants. The patients responded to structured interviews and to a dossier of validated questionnaires to assess the socio-demographic characteristics, the traumatic experience and its psychopathological consequences. The research shows that opioid addiction is positively correlated with social situation, current dissociative symptoms and hyper responsiveness of PTSD. In conclusion, our research provided elements of understanding of the links between PTSD and opioid addiction, thus contributing Iraq researches in the field of addictions. Our study highlight the need to rigorously investigate the presence of traumatic events and include a Cognitive Behavioral Therapy CBT psychotherapeutic intervention targeting PTSD in the treatment of heroin addiction.
\end{abstract}

Keywords: Opioid addiction, post-traumatic stress disorder, dissociation. 


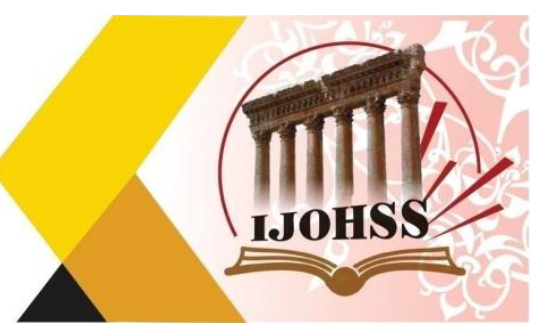

\section{Introduction}

Opioid addiction is a real public health problem. Indeed, according to Iraq Observatory for Drugs and Addiction IODA and National Institute for Prevention and Health Education NIPHE data, heroin use affected 80,000 people in 2020 among individuals aged 11 to 75 years. There were 22,000 four years earlier! These statistics highlight a particularly serious phenomenon requiring collaborative work between all actors in society. If heroin use is problematic, opioid addiction is also on the rise. It should be noted that for the year 2016, 15,000 people benefited from opioid substitution treatment in the Ibn Rushd Psychiatric Hospital Teaching IRPHT or in town medicine in Baghdad compared to 5,000 in 2014 (Youssef, 2020). These statistical data show that the modalities of major opioid use (heroin, morphine, methadone, subutex) have been progressing steadily and continuously in recent years. As a result, it becomes necessary to better understand the causes of opioid addiction. Among the major opiates (morphine, methadone, subutex, skenan, etc.), heroin holds a special place. Discovered in 1874 by Wright and then modified in 1898 by Dreser, the product is obtained by synthesis from morphine, which is itself derived from the poppy. This opiate can be in the form of powder or granules to be crushed. Heroin can be used in a number of ways, including intravenously, by insufflation ("sniffing"), snuff, or smoke. It is often sought after for the physical and psychological well-being it provides. Indeed, it causes a euphoric action, analgesic and anxiolytic effects and dependence. When consumed in high doses, it causes a disturbance of blood circulation and respiratory depression, which can lead to death ("overdose"). Consumption of this product therefore exposes the consumer to serious health risks.

According to the DSM-5 criteria (APA, 2015), opioid use disorder leads to impaired functioning or to clinically significant suffering, characterized by the presence of at least two manifestations out of a series of 11 criteria over a period of 12 months (criterion A). Among the diagnostic criteria, we find persistent desire or fruitless efforts in the patient to reduce or control the use of opiates (criterion 2).

The urge ("craving") in the patient to use opiates (criterion 4) or pharmacological criteria (criterion 10 and 11) such as tolerance and withdrawal. At the criteria level pharmacological, it is indicated in the new edition of the DSM, that tolerance and withdrawal are not considered valid in the development of the diagnosis for people who take opiates only under medical supervision such as methadone hydrochloride, buprenorphine.

The international literature emphasizes that heroin-addiction patients have more significant psychiatric disorders than in the general population. At the level of troubles psychiatric, related to opioid addiction, we note the presence of depressive disorders (Frischknecht, Beckmann, Heinrich, Kniest, Nakovics, Keefer, Mann, \& Hermann, 2011). We also note the presence of psychotic disorders including schizophrenia with addiction on opiates (Picken \& Tarrier, 2011). 


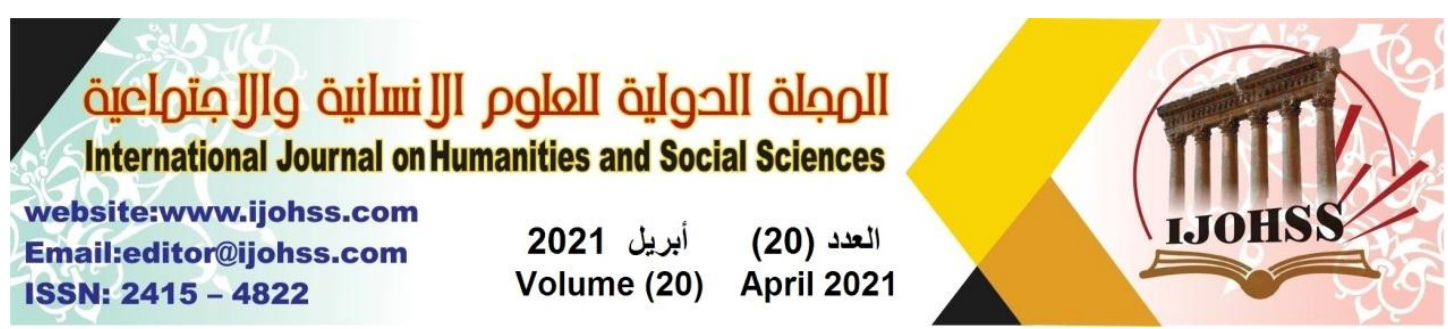

In addition, many previous studies confirmed that opioid addiction patients are not married, they live alone and they receive social benefits to meet their needs. (Norman et al., 2007; Frishknecht et al., 2011; Chung-Hung, Tro-Jen et al., 2015). The heroin addicts have difficulties with employment, and they have not benefited in their life from vocational training giving them access to a profession. (Brewer et al., 1998; Malow et al., 2006: and Bohnert et al.,2009). It has been widely demonstrated also that heroin addicts present health problems due to the use of substances (weight loss, sepsis, arterial hypertension, endocarditis, etc.), and they also present infectious pathologies, such as for example the human immunodeficiency virus HIV, Hepatitis B virus HBV, and Hepatitis C virus HCV. (Bohnert et al., 2009; Chun-Hung et al., 2015).

Numerous studies highlight the relationship between anxiety disorders (as listed in DSM-IV-TR; APA, 2003) notably Post-Traumatic Stress Disorder (PTSD) which is associated with opioid addiction (Evren et al., 2013; Johnson et al., 2006; Mills et al., 2005). Indeed, Cottler et al. (1992) also defended the idea that the consumption of substances such as cocaine and opiates predict PTSD.

This conception is shared by other authors like Johnson et al., (2006) where opioid use is considered a risk factor for exposure to traumatic events and developing PTSD. In other words, heroin users will engage in risky behaviors in order to stock up on drugs including heroin, they expose themselves to traumatic episodes such as physical attacks and they increase the likelihood of developing PTSD. (Reed et al., 2007; Vetter et al., 2008).

According to several analyzes epidemiologically, it is observed that the prevalence rate of PTSD is $40 \%$ in heroin- addiction patients (Mills et al., 2005). The link between PTSD and opioid addiction has therefore been attracting the attention of researchers in recent years.

Finally, several studies show that PTSD is involved in the relapse phases of opioid consumption, thus complicating the management (Hien, Cohen, \& Campbell, 2005; Norman, et al., 2007; Read, Brown, \& Kahler, 2004; Schiff et al., 2010). These observations are consistent with the work of Ford et al (2007). It therefore becomes necessary to better understand the causes of opioid addiction and to pay particular attention to the role of PTSD in the development of heroin addiction, especially in Iraq. Indeed, research on the links between PTSD and heroin addiction is discussed extensively in Asia and some of Arab and regional neighboring countries... but is the subject of rather confidential research in Iraq. In addition, we find that the authors do not always pay exhaustive attention to the psychological and psychopathological vulnerability factors involved in the association of PTSD and heroin addiction.

\subsection{Acute Stress Disorder (ASD): Semiology, epidemiology and risk factors}

According to the DSM-5 (APA, 2015), Acute Stress Disorder (ASD) lasts a minimum of 3 days up to 1 month after exposure to the traumatic event. On the semiological level, the disorder is manifested by the presence of 5 categories of symptoms, including 3 that refer to Post Traumatic Stress Disorder (PTSD), such as symptoms invasive (B1 to B4), avoidance symptoms (B8 to B9), arousal symptoms (B10 to 


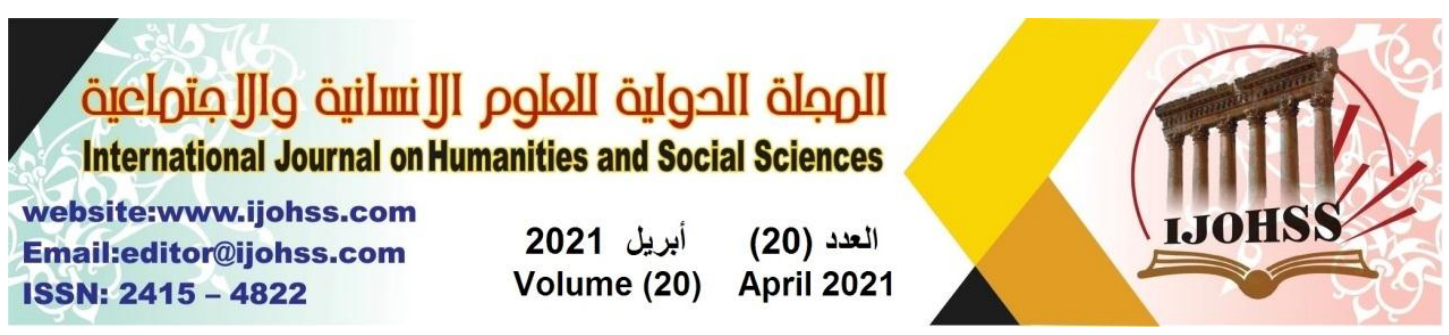

B14), 1 symptom which concerns dissociative manifestations (depersonalization, derealization and dissociative amnesia), and a final one which refers to negative mood referring to the inability of the individual to experience positive emotions (B5) (ASD criteria according to DSM-5). The authors of the latest DSM (APA, 2015) recommend that the diagnostic threshold be set at 9 or more symptoms that encompass the 5 categories of symptoms described previously (Criterion B). Epidemiologically, the study by Bryant \& Harvey, (2003), carried out on a population of road accident victims $(\mathrm{n}=171)$, indicates a prevalence rate of Acute Stress Disorder (ASD) predominant in women $(23 \%)$ compared to men $(8 \%)$. According to the researchers, the gender differences in the psychopathological response to the traumatic event are due to biological factors. In other words, women are at greater risk than men of developing ASD after exposure to the traumatic event.

Regarding risk factors for ASD, according to the DSM-5, psychiatric history, neuroticism, a coping style focused on avoidance are predictors of ASD. In addition, scientific data shows on the one hand that traumatic events such as sexual assault, accidents, natural disasters, etc., represent a necessary condition for the development of the disorder, and on the other hand it is mentioned that the psychological factors exert an influence in the onset of ASD (Bryant et al., 2012).

Many researchers like Birmes and colleagues in 2003, as well as those of the latest version of the DSM (APA, 2013), consider that the persistence of symptoms of ASD beyond one month after the traumatic event results in PTSD. Indeed, if we consider that the signs of arousal such as hypervigilance, irritability and sleep disorders will be decisive in the diagnosis of ASD, their persistence can also promote the appearance of subsequent disorders, including PTSD.

In the psychopathological reactions consecutive to a traumatic event, we note the presence of signs of pertraumatic dissociation (Marmar, Schlenger, Fairbank et al., 1994). In psychiatric nosography, peritraumatic dissociation belongs to the diagnostic criteria (B6 and B7) of Acute Stress Disorder (APA, 2013). The duration of these dissociative states is variable. Indeed, they can occur for a few seconds, sometimes a few hours to a few days.

This is manifested by signs of derealization, depersonalization, restriction of environmental awareness, and dissociative amnesia (APA, 2013). It is important to note that this psychological response occurring during and following the traumatic event has a specific function in the victim in the management of psychotrauma (the term psychotrauma is often used in the Iraqi clinic instead of the term PTSD). According to Salmona (2012), the symptoms of peri-traumatic dissociation are considered to be "self-treatment" behaviors allowing the individual to anesthetize his psychological distress linked to the trauma.

Regarding the course of the disorder, much research has shown that peritraumatic dissociation disorder promotes the onset of PTSD (Birmes, Brunet, Carreras, Ducassé, Charlet, Lanque, Sztulman, \& Schmitt, 2003; Brown, Nugent, \& Hawn, 2016; Bryant, Brooks, \& Silove, 2011). 


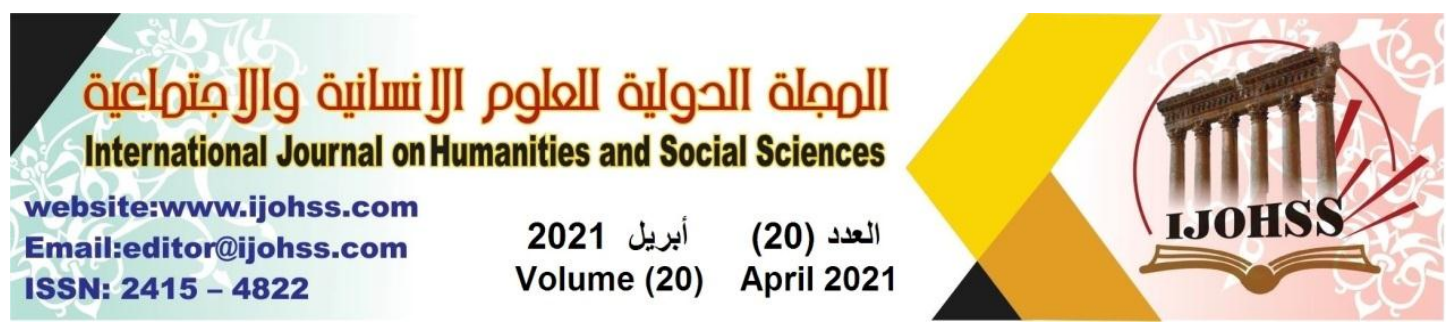

Finally, many studies indicates that peritraumatic dissociation disorder, specifically the signs of derealization, promote the development of PTSD. These studies converge with those of Birmes et al., (2003) and Brown, Nugent, \& Hawn, (2016) where it is shown that pertraumatic dissociation disorder is a predictor of PTSD, hence the need to early detection of dissociative disorder after exposure to the traumatic episode (Weiss \& Marmar, 1997).

\subsection{Post-Traumatic Stress Disorder (PTSD): Semiology epidemiology and risk factors}

As previously mentioned, Acute Stress Disorder as well as Peritraumatic Dissociation Disorder are psychiatric consequences of the traumatic event. We notice that when the clinical signs of ASD intensify over time (greater than 1 month) more precisely with the recurrence of arousal symptoms (criterion 10 to 14), we note the appearance of Post-Traumatic Stress Disorder (309.81 (F43-10)) in the person (criteria of PTSD according to DSM-5.

PTSD therefore sets in 1 month after experiencing traumatic events in the continuity of ASD. In fact, on a semiological level, DSM-5 presents 4 groups of symptoms, i.e. 20 clinical signs associated with PTSD (APA, 2015). We note first the appearance of overwhelming symptoms (memories, dreams, dissociative reactions) which revive the traumatic event (s), causing a feeling of psychological distress (B4), which is accompanied by physiological reactions when the person is exposed to cues (internal or external) referring to an aspect of the traumatic event (s) (B5). With the symptoms of traumatic repetition are added signs of avoidance where the person avoids all internal stimuli (memories, thoughts, feelings) and / or external stimuli (people places, conversations, situations...) associated with one or more traumatic episodes ( $\mathrm{C} 1$ to C2). There are also negative alterations in cognitions and mood, such as example dissociative amnesia (D1), a persistent inability to experience positive emotions (D7), a disinvestment from formerly engaged activities (D5), and feeling of detachment from others (D6).

Finally, there are signs of alterations in arousal and reactivity (neurovegetative activation) such as irritability or outbursts of anger (E1), hypervigilance (E3), concentration disorders (E5), sleep disorders (E6). Still in the criterion of PTSD, the person in response to the stressor may also present symptoms of dissociation (depersonalization or derealization). It should be noted that the persistence of symptoms of PTSD lasts longer than one month. In addition, the signs clinical PTSD can become chronic, that is, it can last for more than 12 months and sometimes for more than 50 years in some individuals (APA, 2013).

Regarding risk factors for the development of PTSD, many studies highlight the role of the severity of traumatic events, such as physical and sexual assault (Frans, Rimmö, Aberg, \& Fredrikson, 2005; Husky et al., 2015), psychiatric history, personality traits of the person, such as neuroticism (Bramsen Dirkzwager, \& Van der Ploeg, 2000; Holeva \& Tarrier, 2001; Breslau, 2002; Jakscic, Brajkovic,et al., 2012), low socioeconomic level (Brown et al., 2016; Foa et al., 2006). 


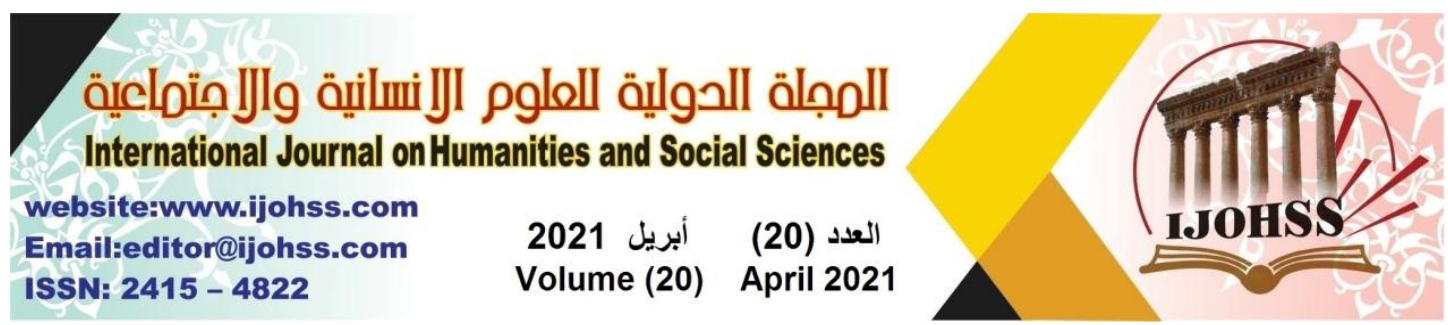

The international literature highlights the role of traumatic events experienced during childhood (Breslau 2002; Husky et al., 2015) as well as the presence of psychopathological manifestations, such as peritraumatic dissociation disorder and Acute Stress Disorder in the onset of PTSD (Birmes et al.,2003; Brown et al., 2016; Bryant et al., 2012).

In addition, Psychiatric literature has amply demonstrated that PTSD is a comorbidity of heroin addiction (Ford, Gelernter, De Voe, Zhang, Weiss, Brady, Farrer et al., 2009; Mills et al., 2005 ; Schiff et al., 2010). We note that PTSD is often associated with other psychiatric disorders such as depressive and anxiety disorders (Blanchard, Buckley, Hickling, \& Taylor, 1998; Blanchard, Hickling, Freidenberg, Malta, \& Kuhu, 2004; Gilbar, 2020; Sareen, Cox, \& Stein, 2007). It is also noted that the risk of suicide is high in individuals with PTSD (Tarrier \& Gregg, 2004; Samantha, et al.,2020). It is observed that PTSD is frequently linked to a substance use disorder (Najavits, Harned, \& Gallop, 2007). In other words, numerous studies reveal that PTSD has an influence in the development of an addictive pathology (Cacciola, Koppenhaver, Alterman, \& Mckay, 2009; Driessen, Schulte, Luedecke, Schaefer, Sutmann, Ohlmeier et al., 2008).

Finally, we note that traumatic events (assault, accidents, bereavement, etc.) can lead to the consumption of over-the-counter (tobacco, alcohol) and prohibited substances (cannabis, cocaine, heroin, etc.) which will gradually lead to addiction in the individual (Brady, Killeen, Brewerton, 2000; Evren, Ozcetinkayer, Ulker, Cagil, Goknalp, Cetin, \& Yigiter, 2012; Gratz, Tull, Baruch, Bornovalova, \& Lejuez, 2008; Stewart, 1996). We note also that the precocity of heroin use is linked to the consumption of tobacco and alcohol. (Leatherdale, \& Burkhalter, 2012: Sartor et al., 2014).

\subsection{Dissociative Disorders: Semiology, Epidemiology and risk factors}

Among the "classic" consequences of traumatic events is the presence of dissociative disorders after exposure to one or more traumatic events occurring in the patient, such as sexual assault, accident, natural disaster or bereavement.

Pierre Janet modeled these post-traumatic psychopathological phenomena at the end of the 19th century. In line with Janet's theory, the authors of DSM-5 (2015) describe dissociative disorders as a disturbance and / or discontinuity in the normal integration of consciousness, memory, identity, emotions, perception, body representation, motor control and behavior.

In the latest version of the DSM (APA, 2015), dissociative disorders are divided into two categories. On the one hand, positive dissociative symptoms, such as dissociative identity disorder, depersonalization, derealization, which testify to a loss the continuity of subjective experience, and on the other hand, negative dissociative symptoms, such as dissociative amnesia, which manifests itself in the individual as an inability to access certain information, which is normally easily accessible to consciousness. 


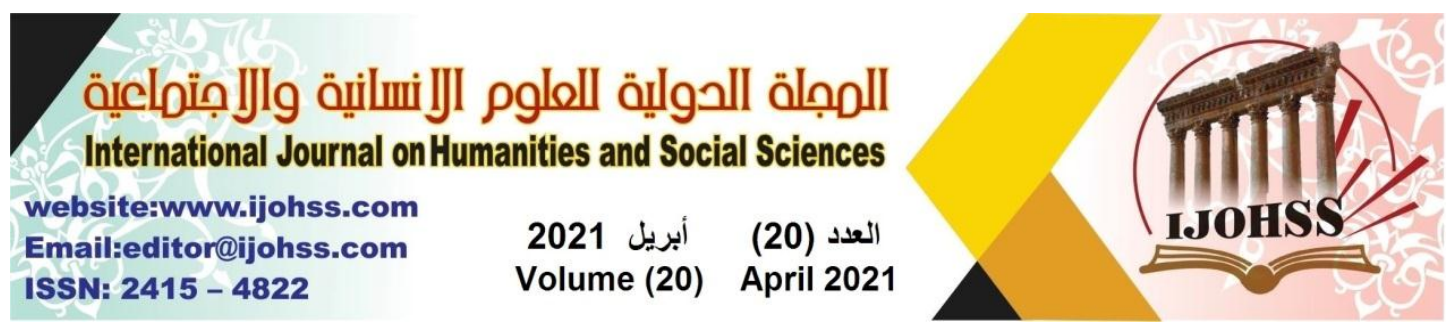

Dissociation disorder has been the subject of numerous studies in psychiatry and addiction medicine. Regarding the heroin-addiction population, several studies have indicated that heroin addiction comorbid with dissociative disorders (Horton, Diaz, Peluso, Mullaney, Weiner \& Mcllveen, 2009 ; Somer, Altus, \& Ginzburg, 2010). Regarding psychiatric comorbidity in opioid addiction individuals, a number of research studies have demonstrated the association between traumatic events and dissociative disorders in heroin addicts. Then, some authors show that the signs of dissociation are comorbid with PTSD (Sar et al., 2004).

These links between the traumatic event, dissociation and PTSD have attracted the attention of researchers who have proposed several models of explanations for the origin of this comorbidity.

In addition, the dissociative disorder associated with PTSD can progress to an addictive pathology such as heroin addiction (Najavits, 2012; Price \& Herting, 2013; Schaëfer et al., 2010; Teesson et al., 2005). The patients on OST and with dissociative disorders encounter, on the one hand, medico-socio-psychological difficulties, and on the other hand, they present difficulties associated with the use of tobacco, alcohol and drugs (Evren et al., 2013 ; Najavits, 2012 ; Salmona, 2012 ; Schaëfer et al., 2010 ; Scioli-Salter, Johnides, Mitchell, Smith, Resick, \& Rasmusson, 2016 ; Somer,2010;Taner, Acikyurek, Cosar, \& Arikan, 2006). These post-traumatic psychiatric manifestations (self-harm, suicide attempts, alcohol and drug consumption, etc.) are considered to be "self-treatment" behaviors which dissociate and which are used by the patient in order to provoke an emotional anesthesia and physical to calm the anxiety related to the traumatic event (Salmona, 2012).

\section{Method}

\subsection{Participants}

Our study involved a population of 30 participants Iraqis made up of men $(n=25)$, and women $(n=5)$, aged 18 to 65 . All participants are addicts on opiates. The Patients are residing in Iraq and their mother tongue is Arabic. The research sample consisted of two groups:

Experimental group. Regarding the socio-demographic data of the clinical population $(n=30)$, we note that the majority of patients are men $(n=25)$ and there are only 5 women. The average age of the patients is 42.46 years compared to 40.3 years of the control group. On the professional level, we note that $83.33 \%(n=24)$ of patients on OST experience difficulties related to employment, while $16.67 \%(n=6)$ of them have a professional activity. It should be noted that $60 \%(\mathrm{n}=18)$ of patients have no professional training compared to $40 \%(\mathrm{n}=12)$. In terms of the type of income, Figure 1 below shows that most patients receive financial assistance to meet their needs. Indeed, we notes that $53.33 \%(\mathrm{n}=16)$ benefit from Solidarity Labor Income (SLI), $23.33 \%(\mathrm{n}=7)$ have a pension. On the other hand, we note that $20 \%(\mathrm{n}=6)$ of active patients have a minimum wage. In addition, we see that only one patient has no income. 


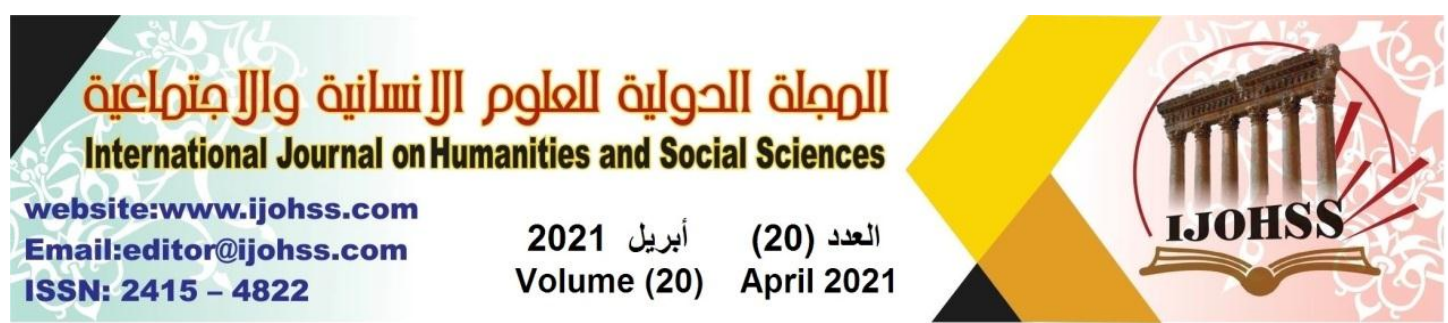

In view of the data related to the civil situation, we notice that the majority of patients, i.e. $83.33 \%(n=25)$ are single while $16.67 \%(n=5)$ are married or live in a couple. Regarding the living conditions of patients on OST, we note that $60 \%$ ( $n=18$ live alone against $40 \%(n=12)$. It appears that $66.67 \%(n=20)$ of patients have a general medical condition, unlike $33.33 \% \quad(n=10)$ of people from the clinical population.

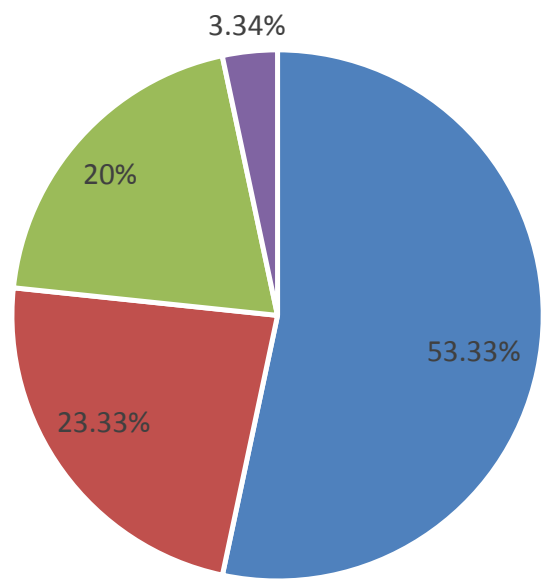

- SLI

- Pension

- Minimum Salary

- Without aids

Figure 1: Type of patient income.

Control group. The control group is made up of 30 men, aged 18 to 65, inactive, living in Baghdad city, married or single, living with their parents or not, and their mother tongue is Arabic. The research focused on individuals who are experiencing professional difficulties, in order to perform comparison analyzes with the clinical population $(n=30)$. Indeed, it has been shown that heroin-addiction patients have employment problems (Mills et al., 2005). Participants are registered with Employment Center in Baghdad. They are not addicted to psychoactive substances including opiates, and they have no psychiatric history. It is important to specify that in accordance with the exclusion criteria that 7 individuals were not included in the control group. Indeed, after studying the data, it was observed that 7 individuals present a tobacco / alcohol codependency.

In terms of socio-demographic data from the control group $(n=30)$, we note that the people are made up exclusively of men $(n=30)$. Regarding the professional situation, we note that all the participants $(n=30)$ are unemployed, $16.66 \%(n=5)$ have not received professional training against $83.33 \%(n=25)$. Regarding the type of income, we note that $76.67 \%(n=23)$ of the control group benefit from the Solidarity Labor Income $(\mathrm{SLI})$, and that $23.33 \%(\mathrm{n}=7)$ receive unemployment benefits. By observing 


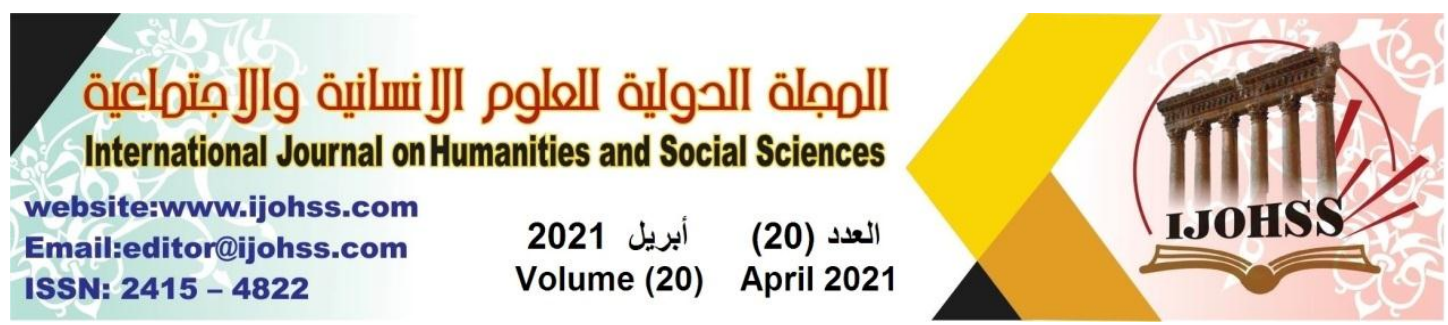

the data from the control situation, it emerges that $43.33 \%(n=13)$ of people are single while $13.33 \%(n=4)$ are married or live in a couple. Regarding the living conditions of people belonging to the control group, we notice that $60 \%(\mathrm{n}=18)$ live alone against $40 \%(\mathrm{n}=12), 26.66 \%(\mathrm{n}=8)$ are divorced and $16.66 \%(\mathrm{n}=5)$ are separated. Finally, only $23.33 \%(n=7)$ of the control group have a general medical condition against $76.70 \%(\mathrm{n}=23)$.

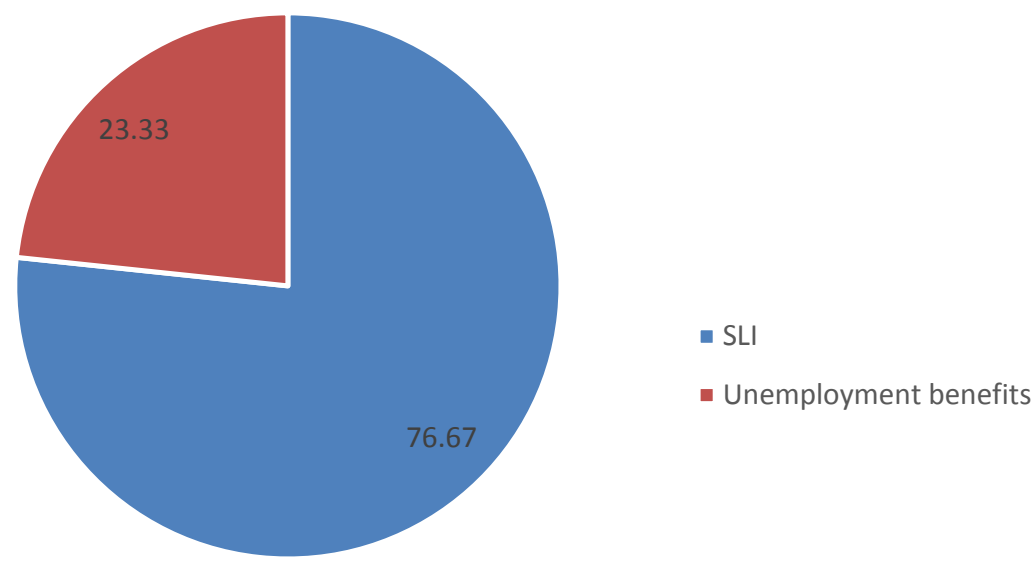

Figure 2. Type of income of control subjects.

\subsection{Materials}

During the research phase, the participants were seen in a semi-structured interview and were subjected to psychological assessments.

We have translated all the tests into Arabic based on the recommendations of the International Testing Commission (2010). Two experienced and bilingual psychologists carried out the translation. The final version of each test was obtained after consultations and agreements between the two translators. The following paragraphs describe these tools in more detail.

\subsubsection{Semi-structured interview: The Addiction Severity Index (ASI)}

The Addiction Severity Index (ASI) by McLellan, Luborsky, \& O'Brien, (1980), is a semi-structured interview made up of 170 questions, or 240 items. The ASI makes it possible to define characteristics related to age, sex, professional situation and to identify elements related to drug consumption including opiates. The ASI lasts 40 to 60 minutes during the first consultation with the patient.

This interview allows a multifactorial assessment to be carried out, focusing essentially on 7 areas: the medical condition, the patient's professional situation and resources, drug consumption, legal situation, family and social relations, psychiatric status. In addition, alcohol use.

Drug use is explored from two periods, in other words, we focus on the use of psychoactive substance throughout the life of the person, and also during the last 30 


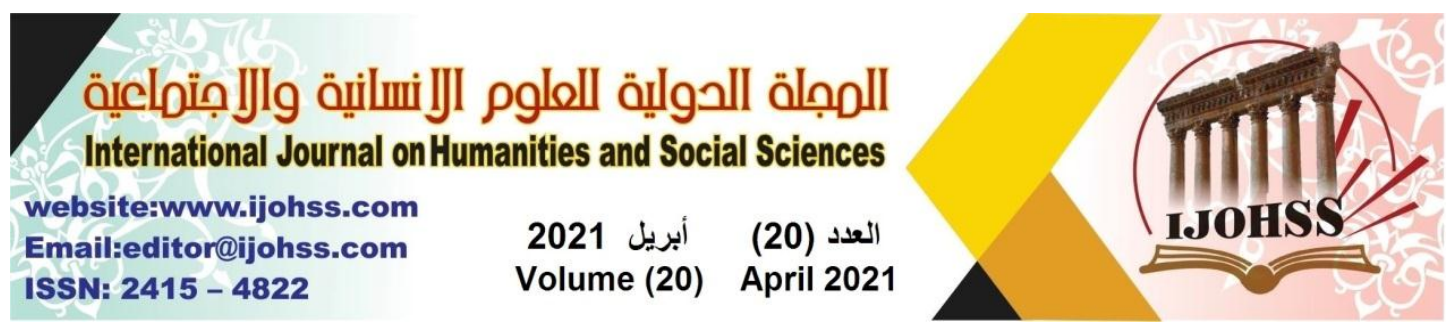

days. Drug use is assessed by a severity score established on a 10-point scale (0 to 9). A score of 4 points reflects problematic drug use, more precisely a need for treatment in this area.

\subsubsection{Drug Abuse Test or Other Drug Abuse Test (DAST-10)}

The Drug Abuse Screening Test (DAST-10) is a test composed of 10 items, allowing the use of drugs, to assess the degree of dependence on psychoactive substances including opiates such as heroin, without taking into account the consumption of alcohol and tobacco.

The tool developed by Skinner (1989) and validated in the Arabic language in several studies. For scoring, one point awarded for each "yes" answer to the test, and no point given for a "no" answer. Then, we add the number of points obtained. Results equal to or greater than 4 points testify to the presence of addiction on drugs such as opiates.

\subsubsection{The Traumatic Life Events Questionnaire (THQ)}

The Trauma History Questionnaire-THQ is a questionnaire developed by Green (1996) to identify traumatic events. It is made up of twenty-four questions addressing several areas such as assault, physical and sexual abuse. For each traumatic event, the patient must specify the number of times and the age when this event occurred.

In terms of scoring, this questionnaire is more of a checklist where the points are divided into five categories (Green, 1996):

0 attacks (from 1 to 4 and from 21 to 23 points),

1 accidents, illnesses, bereavement for the patient and his family ( 5 to 16 points),

2 disasters, wars (6, 7 to 17 points),

3 sexual assault (18 to 20 points),

4 other psychological traumas whose duration is transitory or chronic, such as moral harassment at work

\subsubsection{The Peritraumatic Dissociative Experiences Questionnaire (PDEQ).}

The Peritraumatic Dissociative Experiences Questionnaire (PDEQ) is a ten-item selfevaluation scale that designed by Marmar, Weiss and Metzler (1997). It aims to define the presence and assess the intensity of peritraumatic dissociation reactions, that is, during and after a traumatic event. For each of the items, the individual selects the response that corresponds to the symptoms of dissociation he experienced during and after the traumatic episode.

The rating of the responses varies from 1 (not at all true) to 5 (extremely true). The questionnaire score is obtained by the sum of the items. A fifteen-point result demonstrates that there is a peritraumatic dissociation and a significant risk of developing PTSD. PDEQ used in our research to assess the significance of symptoms of peritraumatic dissociation in opioid addiction patients.

\subsubsection{The Impact of Event Scale Revised (IES-R).}

The IES-R was developed based on the one hand on the Event Impact Scale of Horowitz, Wilner and Alvarez (1979), and on the revision of the latter by Weiss and Marmar (1997). This is a self-report questionnaire to determine the presence of PTSD. 


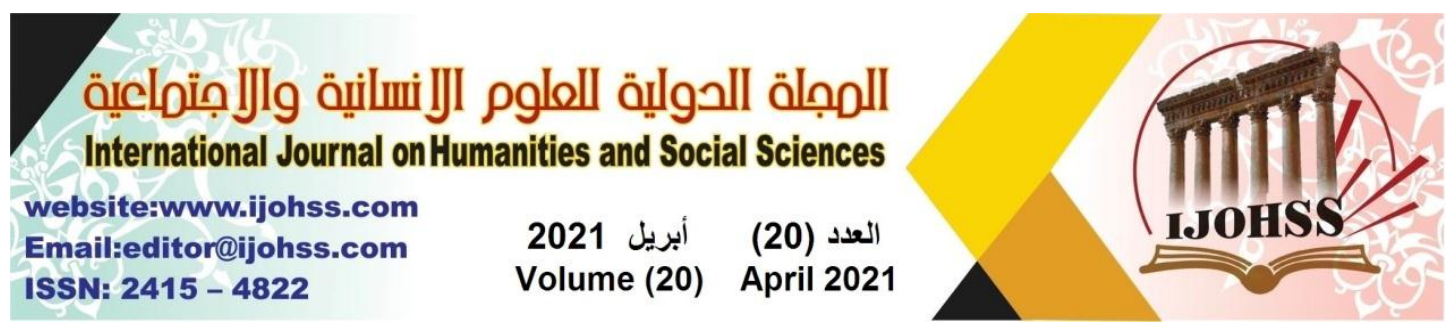

The duration of the passage of the scale is ten minutes. It is made up of twenty-two specific comments related to Post Traumatic Stress Disorder.

The clinical signs of PTSD are divided into the following items:

(1، 2، 3، 6، 9، 14، 16، Intrusion

(5، 7,8،11، 12، 13، 17،22) 1 Avoidance

، 18 ، 19، 21)15، 10، 4 (2 Neurovegetative hyperactivity

The patient gives his answer in relation to the intensity of his experience (not at all $=$ 0 point; a little $=1$ point; moderately $=2$ points; fairly $=3$ points; extremely $=4$ points.)

\subsubsection{The Dissociative Experience Scale (DES)}

The Dissociative Experience Scale (DES) developed by Bernstein et al. (1986) assesses symptoms of dissociation. The DES is the most widely used scale in psychiatry and psychology research to examine dissociative symptomatology. The tool is composed of 28 items that take into account three subscales that refer to dissociative disorders:

1. Absorption in the imaginary, which refers to, items $(2,6,14,15,16,17,18,20,24$, $25,26)$.

2. Depersonalization-Derealization, which concerns the items $(7,11,12,13,19,21$, $22,23,27,28)$.

3. Dissociative amnesia which is related to the items $(1,3,4,5,8,910)$.

At the test level, the patients gives his answer to each item next to $0 \%$ (Not at all) to $100 \%$ (All the time), thus indicating the level of sensation corresponding to each experience he has had. Regarding the quotation, it is noted that the higher the score for the 3 factors, the more the patient will present symptoms of dissociation. The psychometric qualities of the scale are satisfactory (Darves-Bornoz, Degiovanni \& Gaillard (1999). The administration of DES is estimated to take 10 to 15 minutes. In our research, we used DES to assess symptoms of dissociation opioid-addiction patients. Before taking DES, the patients are informed whether they had consumed substances or alcohol before the onset of symptoms, in order to better determine dissociative disorders.

\section{3. Procedure}

This study took place at the IRPHT in Baghdad. The structure offers outpatient care and treatment for patients with addiction with or without psychoactive substances. The patients were recruited from their reception structure after medical consultations. The persons belonging to the control group were contacted by the Employment Center agency located in Baghdad.

The protocol was approved and validated by an ethics committee made up of professors from the Faculty of Medicine of the University of Baghdad. All the participants in this study had previously received a letter of information and had given their informed consent as part of our research.

\section{Resultats}




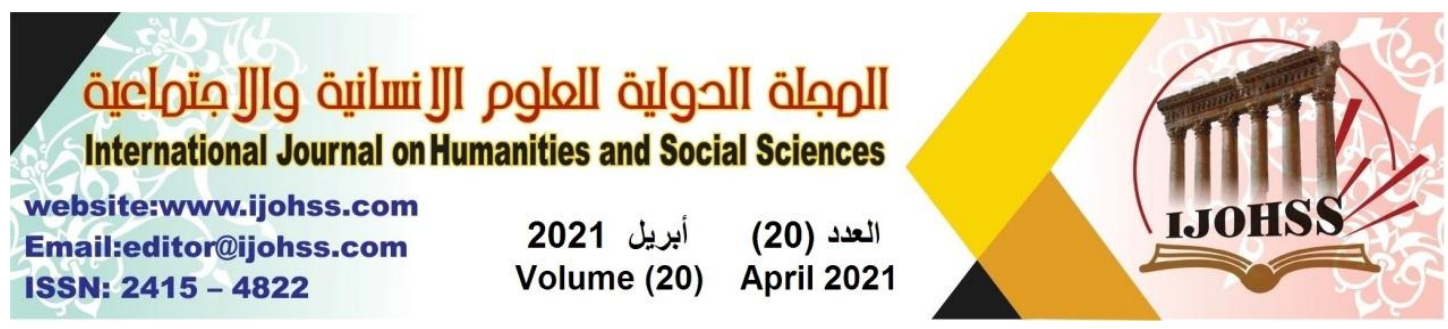

\section{Descriptive analyses}

The following table presents the results of patients $(n=30)$ on ASI. There is no standard for this interview, but the authors (McLellan, Luborsky, Woody, and O'Brien. 1980) retain the threshold score of 4 in order to identify the problem of patients in the fields (Medical, Employment, Tobacco, Legal situation, Social situation, Psychological state, Alcohol, Drugs). Note that the median on the eight subscales is close to the mean, thus showing that the distributions are normal.

Table 1: Presentation of data from opioid addiction patients to the ASI

\begin{tabular}{|c|c|c|c|c|c|c|c|}
\hline $\mathrm{U}$ & Median & Sum & & & $\operatorname{Max}$ & mode & \\
\hline Medical & 5.60 & 3.58 & 6.50 & 168 & 9 & 0 & \\
\hline Employment & 6.20 & 3.26 & 8 & 186 & 8 & 0 & \\
\hline Tobacco & 5.66 & 3.53 & 8 & 170 & 8 & 0 & \\
\hline Judicial & 5.63 & 2.98 & 6 & 169 & 6 & 0 & \\
\hline Social & 5.80 & 2.83 & 6 & 174 & 6 & 0 & 9 \\
\hline Psychological & 7.63 & 1.90 & 8 & 229 & 9 & 0 & 9 \\
\hline Alcohol & 1.66 & 2.94 & 0 & 50 & 0 & 0 & 8 \\
\hline Drug & 8.80 & 0.66 & 9 & 264 & 9 & 6 & \\
\hline
\end{tabular}

$\mathbf{N}=30 \quad$ Threshold score $=4$

We obtain an average of 5.60 (standard deviation of 3.58) with a median of 6.50 on the Medical subscale. The scores in our population range from 0 to 9 with a mode of 9. The results show that the patients present with health problems requiring treatment. On the Employment sub-scale, there is an average of 6.20 (standard deviation of 3.26) with a median of 8 . The scores range from 0 to 9 with a mode of 8 . The data show that the patients encounter related difficulties. To the professional situation. We observe on the Tobacco subscale that the mean is 5.66 and the standard deviation is 3.53 . The median is at 8 . scores range from 0 to 9 , with a mode of 8 indicating problematic tobacco use in patients.

For the judiciary, there is an average of 5.63 (standard deviation of 2.98) with a median of 6 . Scores range from 0 to 9 , with a mode of 6 , thus showing notable problems concerning the judicial situation. For the social situation subscale, we note an average of 5.80 (standard deviation of 2.83) with a median of 6 . The patients' scores range from 0 to 9 with a mode of 6 . These elements indicate that the patients meet social difficulties. At the psychological level, the mean is 7.63 (standard deviation of 1.90) with a median of 8. scores range from 0 to 9 and the mode is 9. These data reveal that patients present with psychological disturbances requiring attention. Appropriate treatment (medical and / or psychotherapeutic). For alcohol consumption, the mean is 1.66 (standard deviation 2.94) with a median of 0 . These data range from 0 to 8 and the mode is 0 , thus demonstrating non-problematic alcohol consumption among patients on OST. 


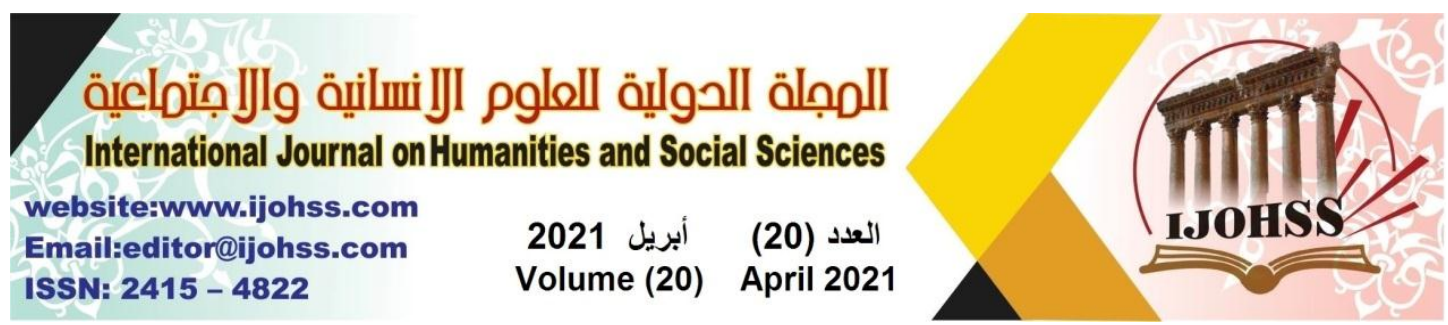

With regard to drug consumption, the average is 8.80 (standard deviation of 0.66 ) with a median of 9 . The data range from 6 to 9 with a mode of 9 . The results attest, on the one hand, to the presence of drug addiction. In fact, the patients are under opioid substitution treatment (OST), they take their daily treatment consisting of methadone or subutex as appropriate. On the other hand, these results take into consideration of the phenomenon of poly-consumption and / or co-dependence on substances in patients.

Table 2 shows the results obtained by the control group at the ASI. We note an average of 0.76 (standard deviation of 1.25) with a median of 0 on the Medical subscale. Scores range from 0 to 4 with a mode of 0 . These data show that people do not encounter any health problems. We obtain an average of 6.50 (standard deviation of 1.07) with a median of 6 on the Employment subscale. The marks range from 5 to 9 with a mode of 6 attesting that the people belonging to the control group have difficulties related to the job.

Table 2: Presentation of data from control group to the ASI

\begin{tabular}{|c|c|c|c|c|c|c|c|}
\hline $\mathrm{U}$ & Median & Sum & & & & mode & \\
\hline Medical & 0.76 & 1.25 & 0 & 23 & 0 & 0 & \\
\hline Employment & 6.50 & 1.07 & 6 & 195 & 6 & 5 & \\
\hline Tobacco & 1.93 & 1.66 & 2 & 58 & 2 & 0 & \\
\hline Judicial & 0.27 & 0.70 & 0 & 8 & 0 & 0 & 3 \\
\hline Social & 0.27 & 0.70 & 0 & 8 & 0 & 0 & Fente \\
\hline Psychological & 1.70 & 1.29 & 2 & 51 & 3 & 0 & strat \\
\hline Alcohol & 0.93 & 0.90 & 1 & 28 & 0 & 0 & \\
\hline Drug & 0.06 & 0.37 & 0 & 2 & 0 & 0 & \\
\hline
\end{tabular}

$\mathbf{N}=30 \quad$ Threshold score $=4$

For tobacco consumption, the mean is 1.93 (standard deviation of 1.66) with a median of 2 . Scores in this area range from 0 to 9 , with a mode of 2 . These data do not reveal problematic tobacco use. On the judicial situation sub-scale, we observe an average of 0.27 (standard deviation of 0.70 ) with a median of 0 . The data range from 0 to 3 with a mode of 0 . These elements clarify that the people of the control group do not present any difficulty at the judicial level. For the situation sub-scale social, we observe an average of 4.63 (standard deviation of 1.93) with a median of 5. The scores in this area are distributed from 0 to 7 and the mode is 5 , testifying that the individuals in the control group have social difficulties.

On the psychological level, there is an average of 1.70 (standard deviation 1.29) with a median of 2 . The scores range from 0 to 4 with a mode of 3 . These data show that the people of the control group do not present no disturbances at the psychological level. Regarding alcohol consumption, we obtain an average of 0.93 (standard deviation of 0.90 ) with the median 1 . These scores range from 0 to 3 with a mode of 


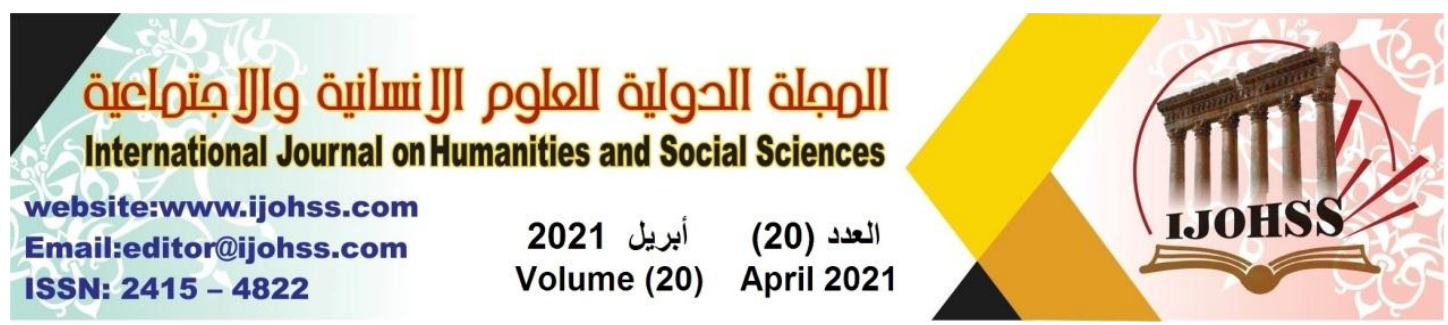

0, thus highlighting that the control group have no problem associated with alcohol use.

\section{Discussion}

Before starting with the interpretation of inferential results (correlations, linear regressions, comparisons), we will first look at the characteristics of the clinical population. After collecting data from the ASI, we observe similarities in sociodemographic factors between our clinical population consisting of patients on OST (n $=30$ ) and other groups of heroin-addiction patients from international literature. First, in terms of professional situation, we observe that $83.33 \%$ of patients are unemployed, $60 \%$ of them have not received professional training. These data converge with those of Bohnert, Bradshaw, and Latkin (2009), Brewer, Catalano, Haggerty, Gainey and Fleming (1998), Malow, Dévieux, Martinez, Peipnan, Lucenko and Kalichman (2006), where it is indicated that opioid-addiction patients have employment-related difficulties and most of them do not have training to enable them to exercise a profession. In terms of living conditions, we note that $76.66 \%$ of the patients in our research live on social assistance, $83.33 \%$ are single and $60 \%$ of them live alone.

These data echo those of other studies, such as those by Norman et al., 2007; Frishknecht et al., 2011 and Chung-Hung, Tro-Jen et al., 2015, where it is mentioned that opioid addiction patients are not married, they live alone and they receive social benefits to support themselves. Finally, in the medical field, we note that $66.67 \%$ of patients under OST have a general medical condition. This result supports data from the medical literature, where it has been widely shown that heroin addicts have health problems due to substance use (Bohnert et al., 2009; Chun-Hung et al., 2015).

The observations from the ASI indicate that the mean ASI Mental score is associated with opioid addiction. This means that patients on OST experience psychological difficulties. This agrees with the studies of Hien et al., 2005; Norman et al., 2007; Read et al., 2004; and Schiff et al., 2010, where it is specified that individuals on methadone suffering from psychological disorders will have relapse phases of heroin and cocaine use thus complicating the therapeutic management. It is also found that the DAST-10 mean is related to the different domains of DES. In other words, patients on OST have a dissociation disorder that manifests clinically with signs of imaginary absorption, depersonalization, derealization, and dissociative amnesia. These data are in line with those found by Horton et al. (2009) and Somer (2010), where it is stated that heroin addiction is co-morbid with dissociative disorders.

The correlation study shows that there is a relationship between opioid addiction and the autonomic hyperactivity of PTSD. Opioid addiction is linked to other signs of PTSD such as intrusion and avoidance.

Therefore, our results are consistent with previous researches (Mills et al., 2005; Ford et al., 2009; Horton et al., 2009). Heroin addiction has been shown to be co-morbid 


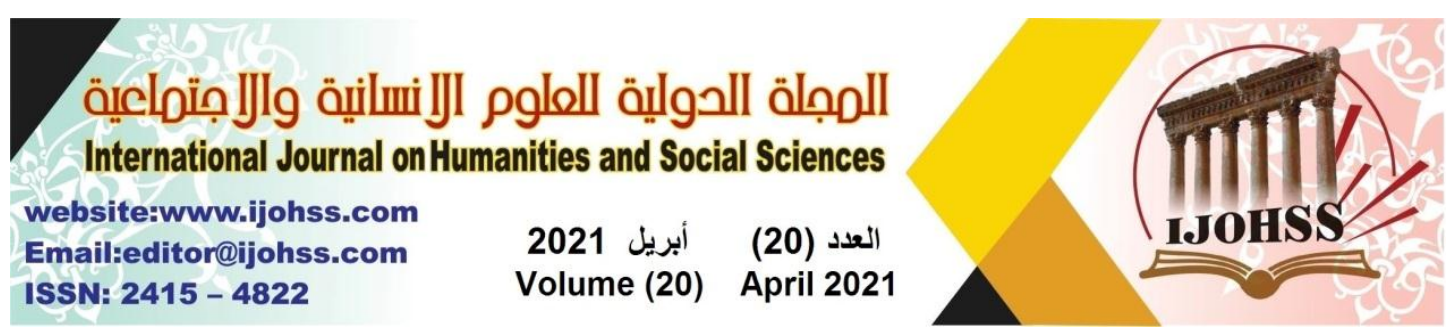

with PTSD in her studies. Specifically, heroin addicts with Post Traumatic Stress Disorder (PTSD) have intrusive symptoms, which are characterized by the sudden and uncontrolled appearance of stimuli (images, thoughts, memories) of the traumatic episode, symptoms of avoidance and hyperarousal. The results of our study indicate that patients on OST suffer from neurovegetative hyperactivity, that is, they have neuropsychological disorders such as disturbances in attention and concentration, sleep disturbances (insomnia ...), Irritability, outbursts of anger.

It is important to add that our results show that there is a correlation between opioid dependence and traumatic events assessed by THQ (Green, 1996;). Our observations agree with previous studies (Brady et al., 2000; Gratz, Tull, Baruch \& Bornovalova, 2008: Stewart, 1996). Indeed, it has been established that traumatic events experienced during childhood are associated with heroin addiction (Evren et al., 2012).

In addition, our results show that 'there is a correlation between opioid addiction and symptoms of peri-traumatic dissociation examined by the PDEQ of Marmar et al. (1997) and Birmes et al (2003). Our results are consistent with previous studies of (Horton, Diaz, Peluso, Mullaney, Weiner \& Mcllveen, 2009 ; Somer, Altus, \& Ginzburg, 2010).

Regarding the study of the links between opioid addiction and socio-demographic factors, it is observed that only social ASI is correlated with DAST-10. This shows that the patients followed for their addiction on opiates encounter social difficulties. Indeed, it is important to remember that $83.33 \%$ of the patients in our study are single and $60 \%$ of them live alone. Our data agree with those from the international literature (Frishknecht et al., 2011; Norman et al., 2007).

After analyzing the socio-demographic variables, our research shows that opioid addiction is not linked to the professional and judicial situation of patients. Our observations contradict previous studies, as there is much research showing that heroin addicts have difficulties associated with employment and they have a civil and / or criminal history (Mills et al., 2005).

During this research, other relationships between clinical data were identified. First, we observe that the DES grades are associated with areas of the ASI (Medical ASI, Tobacco ASI, Social ASI, Mental ASI, ASI Alcohol and ASI Drugs). These results attest that patients on OST and with dissociative disorders encounter, on the one hand, medico-socio-psychological difficulties, and on the other hand, they present difficulties associated with the use of tobacco, alcohol and drugs. These objective data join those from other research (Evren et al., 2013; Najavits, 2012; Salmona, 2012; Schaëfer et al., 2010; Scioli-Salter, Johnides, Mitchell, Smith, Resick, \& Rasmusson, 2016; Somer, 2010; Taner, Acikyurek, Cosar, \& Arikan, 2006). In addition, we note that the precocity of heroin use is linked to the consumption of tobacco and alcohol. These data are in line with (Leatherdale, \& Burkhalter, 2012 and with those of Sartor et al., 2014).

It is important to mention that the traumatic events assessed by Green's THQ (1996) are linked to sociological and psychopathological variables such as PTSD and 


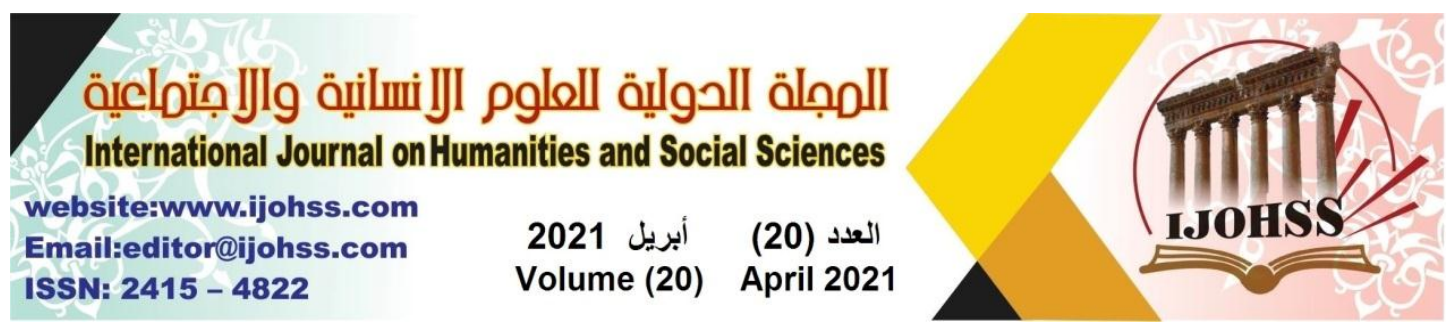

dissociative disorders. These elements agree with researchers from the scientific literature (Evren et al., 2013; Ford et al., 2007; Schiff et al., 2010; Somer et al., 2010). It should be noted that the signs of peritraumatic dissociation are associated with the psychological distress of opioid dependent patients. Taking into account the correlations between PDEQ and IES-R and DES, we notice that they are strong and significant. This demonstrates that the signs of peritraumatic dissociation and PTSD are comorbid and with dissociation disorder. These elements confirm previous data, where it has been clearly established that dissociative states occurring during and after exposure to the traumatic event are associated with PTSD (Birmes, Brunet, Carreros, Ducassé, Charlet, Lanque, Sztulman, \& Schmitt, 2003; Brown, Nugent, \& Hawn, 2016; Bryant, Brooks, \& Silove, 2011).

Finally, the correlational analysis shows that PTSD is associated with many areas of ASI (Employment, Social, Medical) indicating that opioid-addiction patients with PTSD have socio-professional and medical difficulties. These elements are consistent with those of the international literature (Brown et al., 2016; Foa,

Stein \& McFarlane, 2006; Mills et al., 2005). We also note that PTSD is linked to the psychological distress of patients on OST (Mental ASI).

These results are supported by the presence of a comorbidity between PTSD and Dissociation Disorder. To this end, our observations correspond to the psychiatric literature, because several studies show that PTSD is comorbid with dissociation disorder in individuals addiction on opiates (Price \& Herting, 2013; Sar et al., 2004; Schaëfer et al., 2010).

\section{References}

1. APA. (2015). DSM-5, Diagnostic and statistical manual of mental disorder, Fith edition.

2. (2013), Washington DC: American psychiatric Association.

3. Bernstein, EM., Putnam, FW. (1986). Development, reliability and validity of a dissociation scale. $j$ nerv and Ment Dis, 174, 727-734.

4. Birmes, P., Brunet, A., Carreras, D., Ducassé, J.C., Charlet, J.P., Lanque, D., Sztulman, H., Schmitt, L. (2003). The predictive power of peritraumatic dissociation and acute stress symptoms for posttraumatic stress symptoms: A three-month prospective study. Am journal psychiatry, 160(7), 1337-1339.

5. Blanchard, EB., Buckley,TC., Hickling,EJ., Taylor, AE (1998). Postttraumatic Stress Disorder and comorbid major depression is the correlation an illusion. Journal Anxiety Disorder, 12 (1), 21-37.

6. Blanchard, EB., Hickling,EJ., Freidenberg, BM., Malta, LS., Kuhu, E., et al. (2004). Two studies of psychiatric morbidity among motor vehicle accident survivors 1 year after the crash. Behaviour Research Therapy, 42 (5): 569-583.

7. Bohnert, A.S.B., Bradshaw, C.P., Latkin, C.A. (2009). A social network perspective on heroin and cocaine use among adults: evidence of bidirectional influences. Addiction, 104, 1210-1218. 


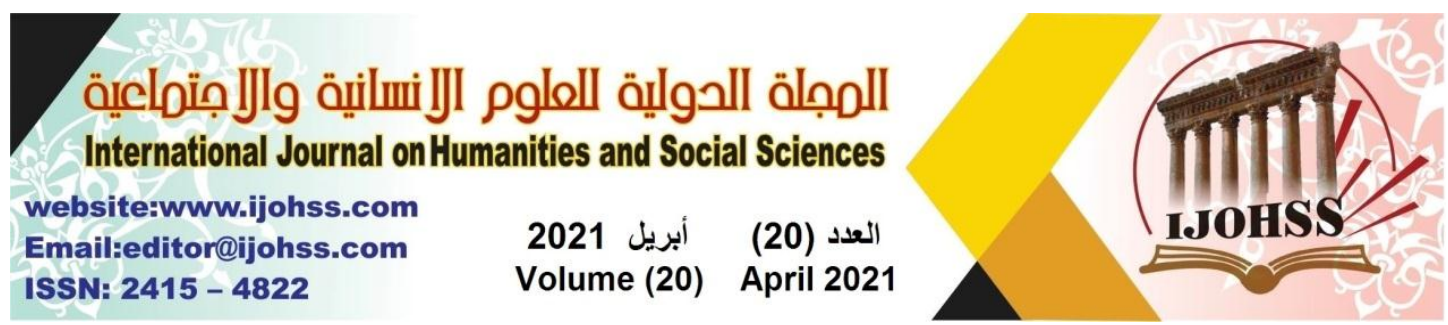

8. Brady, KT., Killeen, TK., Brewerton, T et al. (2000). Comorbidity of psychiatric disorder and posttraumatic stress disorder. J Clin Psychiatry, 61(7): 22-32.

9. Bramsen, I., Dirkzwager, A., Van der Ploeg, H. (2000). Predeployment personality traits and exposure to trauma as predictors of posttraumatic stress symptoms: a prospective study of former peacekeepers. American journal of psychiatry, 157, 1115-1119.

10. Breslau (2002). Epidemiologic studies of trauma, Posttraumatic Stress Disorder and other psychiatric disorder, Can J psychiatry, 47: 923-929.

11. Brewer, D.D., Catalano, R.F., Haggerty, K., Gainey, R.R., Fleming, C.B. (1998). A meta-analysis of predictors of continued drug use during and after treatment for opiate addiction. Addiction, 93 (1), 73-92.

12. Brown, RC., Nugent,NR., Hawn, SE et al. (2016). Predicting the transition from acute stress disorder to Posttraumatic Stress Disorder in children with severe injuries. Journal of Pediatric Health Care, 30, 6: 558-568.

13. Bryant, R.A., Creamer, M., O'Donnell, M., Alexander,DR., Mc Farlane,C. (2012). The capacity of acute stress disorder to predict posttraumatic psychiatric disorders. Journal of psychiatric research, 46, 2: 168-173.

14. Bryant, R.A., Brooks, R., Silove, D., et al. (2011).Peritraumatic dissociation mediates the relationship between acute panic and chronic posttraumatic stress disorder. Behavior research and therapy, 49, 346-351.

15. Bryant, RA \& Harvey, AG. (2003). Gender differences in the relationship between acute stress disorder and posttraumatic stress disorder following motor vehicle accidents. Australian and new Zealand Journal of psychiatry, 37: 226-229.

16. Cacciola, J. S., Koppenhaver,JM., Alterman, AI., Mckay, JR. (2009). Posttraumatic stress disorder and other psychopathology in substance abusing patients. Drug and Alcohol dependence. 101, 27-33.

17. Chun-Hung, L., Tro-Jen,W., et al. (2015).Familial expressed emotion among heroin addicts in methadone maintenance treatment: Does it matter? Addictive behaviors, 45, 39-44

18. Cottler, L.B., Compton, W.M.III, Mager, D., Spitznagel, E.L., et al. (1992). Posttraumatic stress disorder among substance users from the general population. American Journal of psychiatry, 149, 664-670.

19. Darves-Bornoz JM., Degiovanni A., Gaillard P.(1999).Validation of French version of the Dissociative Expériences Scale in a rape-victim population. $J$ Psychiatry 44, 271-275.

20. Driessen, M., Schulte, S., Luedecke, C., Schaefer, I., Sutmann, F., Ohlmeier, M., Kemper, U., Koesters, G., Chodzinski, C., Schneider, U., Broese, T., Dette, C., Havemann-Reinicke, U. (2008).Trauma and PTSD in patients with alcohol, drug, or dual dependence: a multi-center study. Alcoholism: clinical and experimental research, 32, (3), 481-488.

21. Evren, C., Cinar, O., Evren, B., Ulku, M., Karabulut,V., Umut, G. (2013). The mediator roles of trait anxiety, hostility, and impulsivity in the association between 


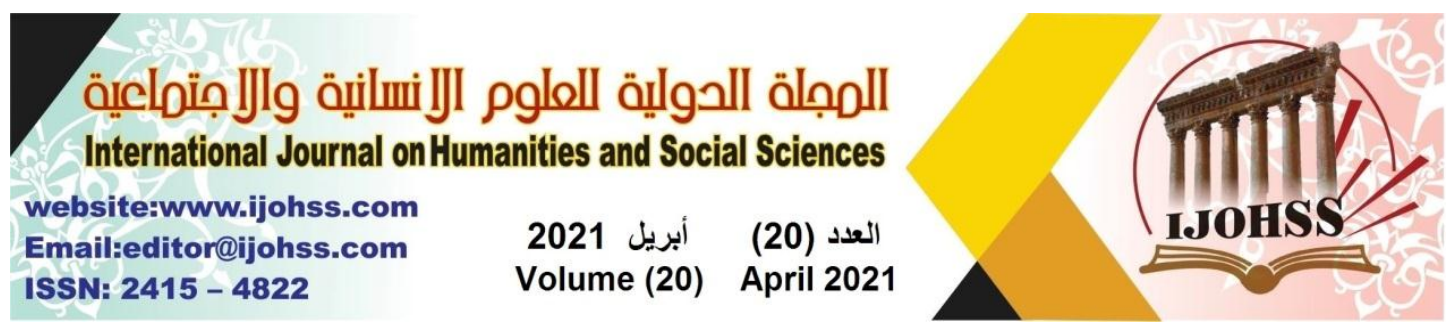

childhood trauma and dissociation in male substance-dependent inpatients. Comprehensive psychiatry, 54, 158-166.

22. Evren, C., Ozcetinkayer, S., Ulker, M., Cagil, D., Goknalp, P., Cetin, T., Yigiter, S. (2012). Relationship of defense styles with history of childhood trauma and personality in heroin dependent inpatients. Psychiatry research, 200, 728-733.

23. Foa, EB., Stein, D.J., McFarlane, A.C. (2006). Symptomatology and psychopathology of mental health problems after disaster. J Clin Psychiatry, 67, 2: $15-25$.

24. Ford, J.D., Gelernter, J., DeVoe, J.S., Zhang, W., Weiss, R.D., Brady, K., Farrer, L., Kranzler, H.R. (2009). Association of psychiatric and substance use disorder comorbidity with cocaine dependence severity and treatment utilization in cocainedependent individual. Drug and alcohol dependence, 99, 193-203.

25. Ford, D.J., Hawke, J., Alessi, S., Ledgerwood, D., Petry, N. (2007). Psychological trauma and PTSD symptoms as predictors of substance dependence treatment outcomes. Behaviour research and therapy, 45, 2417-2431.

26. Frans, O., Rimmö, P.A., Aberg, L., Fredrikson, M. (2005). Trauma exposure and post-traumatic stress disorder in the general population. Acta Psyciatr Scand Apr, 111(4), 291-299.

27. Frischknecht, V., Beckmann, B., Heinrich, M., Kniest, A., Nakovics, H., Kiefer, Mann, K., Hermann, D. (2011). The vicious circle of perceived stigmatization، depressiveness, anxiety, and low quality of live in substituted heroin addicts European Addiction Research, 17, 241-249

28. Gilbar, O. (2020). Examining the boundaries between ICD-11 PTSD / CPTSD and symptoms of depression and anxiety: A network analysis perspective. Journal of Affective Disorder, 262, 429-439

29. Gratz, K.L., Tull, M.T., Baruch, D.E., Bornovalova,M.A., Lejuez, CW. (2008). Factors associated with co-occuring brderline personnality disorder among inner-city substance users. The roles of childhood maltreatment, negative affect intensity/reactivity, and emotion dysregulation. Comprehension psychiatry, 49(6), 603-615.

30. Green, B.L. (1996). Trauma History Questionnaire. In BH Stamm, E.M. Varra (ED), Measurement of stress, trauma, and adaptation (pp.366-369). Catherville, MD: Sidran Press.Greenfield, SF., Strakowski, SM et al. (1994). Childhood abuse in first episode-psychosis. Br J Psychiatry, 164 (6): 831-834.

31. Hien, D., Cohen, L., Campbell, A. (2005). Is traumatic stress a vulnerability factor for women with substance use disorders? Clinical psychology review, 25, 813823.

32. Holeva, V., \& Tarrier, N. (2001). Personality and peritraumatic dissociation in the prediction of PTSD in victims of road traffic accidents. J Psychosoma Res, 51(5): 687-692.

33. Horowitz, M., Wilner, N., Alvarez, W. (1979). Impact of event scale: a measure of subjective stress. Psychosomatic medicine, 41, 209-218. 


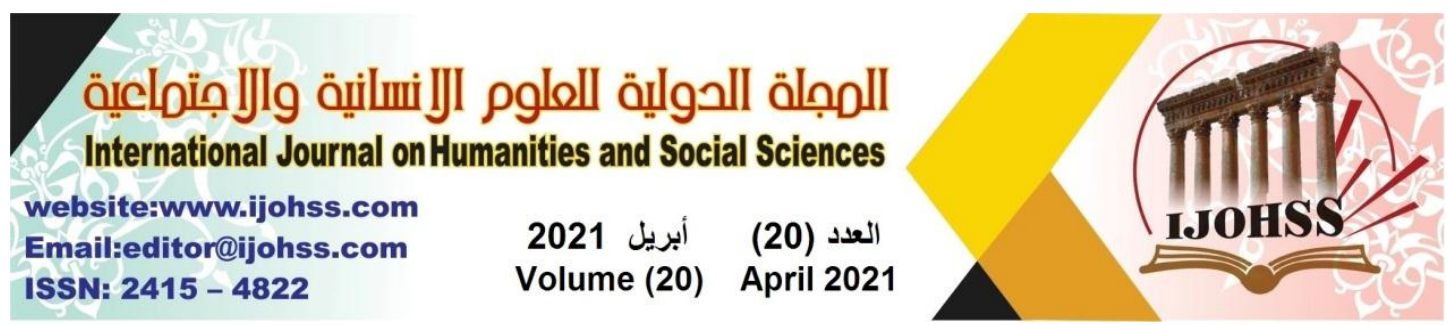

34. Horton, E., Diaz, N., Peluso, PR., Mullaney, D., Weiner, M., Mcllveen, JW. (2009). Relationships between Trauma, Posttraumatic Stress disorder Symptoms, Dissociative Symptoms, and Lifetime Heroin use among individuals who abuse substances in residential treatment. Journal of Addiction \& Offender Counseling. 29, 81-95.

35. Husky, MM., Lépine, JP., Gasquet, I., Kovers-Masfety, V. (2015). Exposure to traumatic Events and Posttraumatic Stress Disorder in France: results from the WMH Survey. Journal of Trauma Stress 28(4), 275-282.

36. Jakscis,N., Brajkovic, L et al. (2012).The role of personality traits in Posttraumatic Stress Disorder (PTSD). Psychiatria Danubina, 24, 3 256-266.

37. Johnson, S,D., Striley C., Cottler, LB.(2006). The association of substance use disorders with trauma exposure and PTSD among African American drug users. Addictive behaviors. 31, 2063-2075.

38. Josse, E. (2007). Le traumatisme psychique quelques repères notionnels.

$39 . \quad$ www.resilience-psy.com.

40. Malow, R.M., Dévieux, J.G., Martinez, L., Peipnan, f., Lucenko, B.A., Kalichman, S.C. (2006). History of traumatic abuse and HIV risk behaviors in severely mentally II substance abusing adults. Journal of family violence, 21(2), 127137.

41. Marmar, C., Weiss, D., Schlenger, W., Fairbank, J et al. (1994). Peritraumatic dissociation and posttraumatic stress in male Vietnam theater veterans. American Journal of psychiatry, 151, 902-907.

42. Marmar, C., Weiss, D., Metzler, T. (1997). The peritraumatic dissociative experience questionnaire. In J. Wilson, \& T. Keane (Eds.), Assessing psychological trauma and PTSD (pp. 413-428). New York: The Guilford Press.

43. McLellan AT., Luborsky L., Woody GE., O'Brien CP.(1980). An improved diagnostic evaluation instrument for substance abuse patients. The Addiction Severity Index. J new Ment Dis. 168 (1), 26-33.

44. Mills, K.L., Lynskey, M., Teesson, M., Ross, J., Darke, S. (2005). Post-traumatic stress disorder among people with heroin dependence in the Australian treatment outcome study (ATOS): prevalence and correlates. Drug and alcohol dependence, 77, 243-249

45. Najavits, LM., Harned, MS ., Gallop RJ.(2007). Six-month treatment outcomes of cocaine-dependent patients with and without PTSD in a multisite national trial. J Stud Alcohol Drugs. 68, (3), 353-61.

46. Najavits, L.M., Walsh, M. (2012). Dissociation, PTSD, and substance abuse: an empirical study. Journal of trauma \& dissociation, 13 (1), 115-126.

47. Norman, S.B., Tate, S.R., Anderson, K.G., Brown, SA. (2007). Do trauma history and PTSD symptoms influence addiction relapse context? Drug and alcohol dependence, 90, 89-96.

48. Picken, A., Tarrier, N. (2011). Trauma and comorbid posttraumatic stress disorder in individuals with schizophrenia and substance abuse. Comprehensive psychiatry 497-490, (5)52 


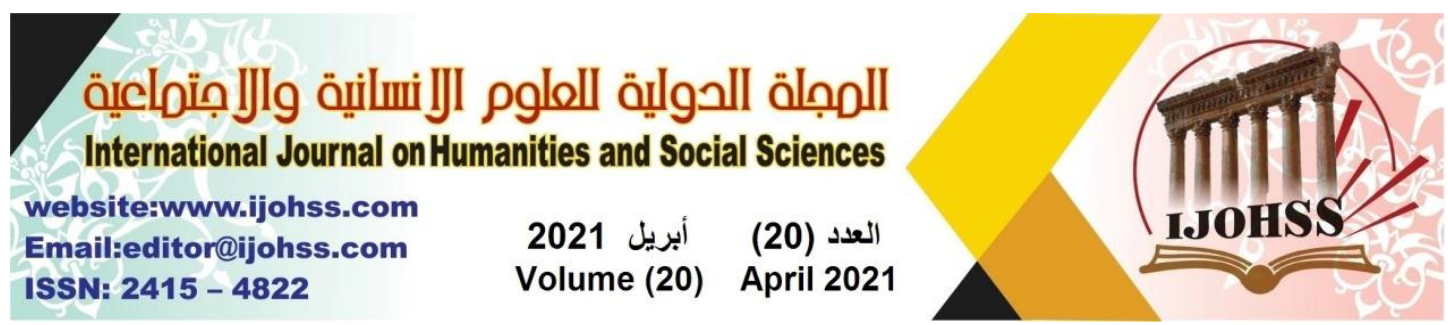

49. Price, C.J., Herting, J.R. (2013). Canges in Posttraumatic stress symptoms among women in substance use disorder treatment: the mediating role of bodily dissociation and emotion regulation. Substance abuse: Research and treatment, 7, 147-153.

50. Read, J.P, Brown, P.J, Kahler, C.W (2004). Substance use and posttraumatic stress disorders: Symptom interplay and effects on outcome. Addictive behaviors, 29(8), 1665-1672.

51. Reed, P.L., Anthony, J.C., Breslau, N. (2007). Incidence of drug problems in young adults exposed to trauma and posttraumatic stress disorder : do early life experiences and predispositions matter? Arch gen psych, 64(12), 1435-1442.

52. Salmona, M. Mémoire traumatique et conduites dissociantes. In Contanceau, RSmith, Traumas et résilience. Dunod (2012).

53. Samantha, A.C., Benjamin R. S., Kipling M. B., Rebecca K. S., John F. M. (2020). Association Between Positive Results on the Primary Care-Posttraumatic Stress Disorder Screen and Suicide Mortality Among US Veterans. Original Investigation Psychiatry. JAMA Network Open.; 3(9):e15707. Doi: 10.1001

54. Sar, V., Akyuz, G., Kundakci, T., Kiziltan, E., Dogan, O. (2004). Childhood trauma, dissociation, and psychiatric comorbidity in patients with conversion disorder. American Journal Psychaitry, 161, 2271-2276.

55. Sareen, J., Cox, B.J, Stein, M.B et al. (2007). Physical and mental comorbidity disability and suicidal behavior associated with posttraumatic stress disorder in a large community sample. Psychosomatic medicine, 69, 242-248.

56. Schaëfer, I., Langeland, W., Hissback, J., Luedecke, L., Kemper, U., et al. (2010). Childhood trauma and dissociation in patients with alcohol dependence, drug dependence, or both-a multi -center study. Drug and alcohol dependence, 109 (1-3), 84-89.

57. Schiff, M., Levit,S., Cohen-Moreno, R.(2010). Childhood sexual abuse, posttraumatic stress disorder, and use of heroin among female clients in Israeli methadone maintenance treatment programs (MMTPS). Soc Work Health Care. 49 (9), 799-813. 58. Scioli-Salter, ER., Johnides, BD., Mitchell, KS., Smith, BN., Resick, PA., Rasmusson, AM. (2016). Depression and dissociation as predictors of physical health symptoms among female rape survivors with posttraumatic stress disorder. Psychological trauma: theory, research, pratice, and policy, 8 (5), 585.

59. Skinner, H.A. (1989). The Drug Abuse Screening Test (DAST): Guidelines for administration and scoring. The Addiction Research Foundation.

60. Somer, E.(2003). Prediction of abstinence from heroin addiction by childhood trauma, dissociation, and extent of psychosocial treatment. Addiction research and theory. 11(5), 339-348.

61. Somer, E., Altus, L., Ginzburg, K. (2010). Dissociative psychopathology among opioid use disorder patients: exploring the "chemical dissociation" hypothesis. Comprehensive psychiatry. 51,419-425.

62. Stewart, SH .(1996). Alcohol abuse in individuals exposed to trauma: a critical review. Psychol Bull, 120 (1) : 83-112. 


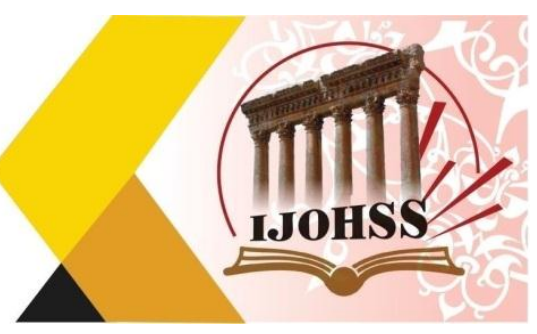

63. Taner, E., Acikyurek, K., Cosar, B., Arikan, Z. (2006). Dissociative disorder in alcohol dependent patients. Journal of dependence, 3th National Addiction Congress (Supl), 7, p.62 (Turkish).

64. Tarrier, N., Gregg, C. (2004). Suicide risk in civilian PTSD patients.Pre'dictors of suicidal ideation, planning and attempts. Social psychiatry and psychiatric epidemiology, 39, 655-661.

65. Teesson, M., Havard, A., Fairbairn, S., Ross, J., Cynskey, M., Darke S.(2005).Depression among entrants to treatment for heroin dependence in the Australian Treatment Outcome study (ATOS) : prevalence, correlates and treatment seeking. Drug and Alcohol dependence, 78, 309-315.

66. Vetter, S., Rossegger, A., Rossler, W., Bisson, J.I., Endrass, J. (2008). Exposure to the tsunami disaster, PTSD symptoms and increased substance use-an internet based survey of male and female residents of Switzerland. BMC, public health, 8-92. 67. Weiss, D.S.\& Marmar, C.R.(1997). The Impact of Event Scale-Revised. In J.Wilson \& T.Keane (Eds), Assessing psychological trauma and PTSD, 399-411. New York Guildford Press.

68. Youssef, D. (2020). Drug trade and abuse in Iraq. https://www.sotaliraq.com. 